\title{
Addressing Cultural Challenges of Teaching English to Chinese Students for Beginning ESL Instructors
}

\author{
Cassie Larson \\ Park University
}

Keywords: Chinese students, teaching English, ESL teaching challenges, cultural challenges

\begin{abstract}
Teaching English to students from an Asian cultural background presents unique challenges. This article uses the author's experience of studying and teaching in China and working with Chinese students in a multicultural context in the USA to identify persistent challenges, share the reasons that she believes are behind these challenges and offer practical solutions that instructors can use in their classroom today. Although the focus is primarily on Chinese students, the information might also be useful for ESL teachers working with other Asian learners. This article brings to attention cultural aspects rather than linguistic aspects.
\end{abstract}

\section{Introduction}

Most instructors who have experience teaching Chinese students are aware of the cultural challenges the students face. As an experienced ESL instructor who studied and taught in China, I find the following seven topics particularly relevant to many students with a Chinese cultural background. ${ }^{1}$ Since I interpret my interactions and experience with Chinese students from a Western perspective, statements in this paper also reveal my North American cultural values. I limit discussion to behaviors which I have seen affect classroom performance in the US:

1. Fear of speaking and making mistakes in class;

2. Communication mainly with other Chinese students;

3. Hesitation with asking questions due to risk of embarrassment;

4. Critical thinking and different perceptions of plagiarism;

5. Tests as the only measure of success in a program;

6. Immaturity by US standards;

7. Privacy and cross-cultural experiences.

\footnotetext{
${ }^{1}$ I studied and worked in Dalian, China during the period from August 2007 to January 2012.
} 
The rest of the paper addresses these behaviors from my personal and professional perspective.

\section{Fear of Speaking and Making Mistakes in Class}

For some ESL instructors it might be surprising to see Chinese students excel on their reading and grammar assignments, or even listening tests, while being unable to hold a beginning level conversation in English. From my personal observation, the Chinese educational system teaches students to be diligent from a young age, listen carefully to the teacher without asking questions, and complete all homework assignments, which often includes memorizing long passages from books. This kind of educational system can produce hard workers who tend not to openly question their assignments or learning outcomes. Language classes in China can have up to 60 students in one class with cramming and test analysis as the main activities. While language is defined as a means of communication, I have observed that even specialized English language schools in China often fail to teach the very basics of oral communication. Adding to this, entire generations of children raised under the one child policy with high expectations of parents and both sets of grandparents, we can imagine students fearing to make mistakes and lose face, which could happen if one speaks up.

So, what can be done to help our Chinese students verbally participate in the US classroom? First of all, they need to feel it is a safe environment. At the start of the term, it is important to reassure the students that mistakes are a natural part of the learning process, and the instructor is there to help them. If they know they can be graded on some assignments according to their efforts and participation rather than accuracy, they may feel more relaxed and therefore progress faster.

Secondly, it is vital to be patient. Students should be given the time they need to get used to the new environment. Pressing students to open up within the first few days might produce additional anxiety. They usually start slowly improving by the end of the second week and progress from then on. It is important to bring balance and gently draw out the students until they feel comfortable enough to actively participate on their own.

Another tool that can be used is creating a WhatsApp or a WeChat group for the students. Students can be encouraged to use the group to ask questions and exchange opinions with one another outside of the classroom. Instructors can guide the conversation, post announcements related to class and social activities on campus, as well as share interesting links for extra practice. Also, such groups help students to connect with their instructor much faster than e-mail or other forms of communication and are particularly helpful in case of emergency.

\section{Communication Mainly with Other Chinese Students}

The tendency to communicate only or mostly with those from one's home country can be common among internationals, including students from China. From my observation, it is rare to see a new Chinese student quickly making friends with other internationals who are not from 
mainland China. This behavior could be consistent with collectivistic behavior as explained in Cherry (2018) about China and collectivistic culture:

In such cultures, relationships with other members of the group and the interconnectedness between people play a central role in each person's identity. Where collectivism stresses the importance of the community, individualism is focused on the rights and concerns of each person. Collectivist cultures are also associated with low relational mobility, a term to describe how many opportunities individuals in a society have in forming relationships with people of their choosing. Low relational mobility means that the relationships people have are stable, strong, and long-lasting. These relationships are usually formed due to factors such as family and geographical area rather than personal choice. Strangers are more likely to remain strangers to those from a collectivistic culture than they would be to people from individualistic cultures (Cherry, 2018).

Although behavior of "staying with the familiar" might be viewed as common, ESL instructors also know that students should interact with local people to enrich the international education experience and more quickly improve their English. How can we help Chinese students better integrate into the larger community while in the US? First of all, peer interaction can be encouraged by pairing Chinese students with those from other countries for in-class partner work. Some may have better reading and listening skills, but may be weaker in terms of speaking and oral fluency. For example, when one of my Chinese students kept asking me for extra listening and speaking homework saying the book was too easy for her, I came up with an idea. Instead of giving her more exercises from the book to do on her own, I asked her to go to the school cafeteria, start a conversation with an American student, talk to the student for at least 20 minutes and at the end do a short voice recording of that student stating her name, major, and the topics they just discussed.

Needless to say, at first the task seemed challenging for my student, who seemed horrified at the idea of initiating a conversation with a stranger. I encouraged her after class and explained the benefits of speaking to other American students. I watched the fear in her eyes slowly giving way to hope, as she reluctantly said, "Ok, maybe I can try." I gave her several days for the assignment. However, the next day she walked up to me with a big smile on her face. "Here," she played the recording. "It worked!" Not only did she get to practice her English for half an hour, but she also made a friend who invited her over to her room the next day to chat and practice more. This was a small victory. It was even hard to determine if it was my student or if it was I who was more excited at that moment. Real and meaningful conversation with a native speaker of English clearly had a more positive effect than another exercise in a book. I believe this was also a turning point for my student. As the months went by, she became actively involved in various international festivals, activities and projects on campus, and her English quickly improved, which was reflected in her grades.

Now, let us move on to the actual class time. For listening and speaking classes, instructors might ask students to survey American peers in the cafeteria or library. Giving them a sample of survey questions may help; however, I find it is best to let them make their own 
questions on the current textbook topic. For instance, if the topic discussed in the textbook is honesty (Scanlon, 2015, pp.120-141), they could potentially create survey questions such as the following:

- How do you define honesty?

- Do you consider yourself an honest person?

- Have you ever been dishonest or told a lie?

- If you were dishonest and did not get caught, would it be okay?

- What would you say to a person who wants to act dishonestly?

After reviewing the students' questions and making the necessary corrections, instructors can ask students to conduct the survey outside of the classroom, having them use a voice recorder to record the answers and then share the recording with the instructor.

In addition to all mentioned above, it is important to encourage students to take part in social activities on campus. From my experience, they are usually more motivated if other people they know also come to the event, so ideally it would be best for the instructor to invite the whole class and to consider participating in the social activities from time to time. If students are presenting or performing, their instructor's support will energize them tremendously.

\section{Hesitation with Asking Questions Due to Risk of Embarrassment}

It can be especially difficult to determine if students are not asking questions out of embarrassment because it may appear that students are not asking because they understand. Even if they say they understand; however, it does not necessarily mean that they do. In Mandarin Chinese, the word “question" (问题) is the same as the word "problem." I interpret the dual meaning of the word as a way of understanding my observation that many Chinese students do not want to cause problems, so they prefer not to ask questions. In fact, they can see Western students' behavior as disrespectful when they ask instructors questions. It can simply be difficult for the students to understand that it is appropriate to disagree in the US classroom.

Therefore, during the first encounter with students, instructors can make clear that they expect to hear different opinions during discussion, and that students do not have to agree with them or anyone else. Students need to know they are expected to ask questions as long as the questions are related to the topic. I find it more helpful if the students are not even given a yes/no answer option. When students voice their questions, instructors should pay attention to their facial expressions and never make comments that would imply the question was strange, or it might shut the students down. Instructors might, instead, offer positive feedback, such as, "Thank you for your question, Lee. Yes, this is interesting," and then proceed to answer the question.

\section{Critical Thinking and Different Perceptions of Plagiarism}

From my personal observation, Chinese students are encouraged to copy and cram from a very young age. There is little place for creativity. For instance, I had college students unable to analyze a reading passage and think how it could be applied to real life. Instead, they would read 
it out loud all over again. They would rather memorize the whole page than think of how it could be analyzed or interpreted. From what I have seen, students at Chinese schools have to memorize enormous amounts of information, often without thinking or knowing how it can possibly be applied or connected to prior knowledge. The research shows that while this is an effective strategy for tomorrow's test, it is highly ineffective in the long run, as there is very little retention. Brown, Roediger, and McDaniel (2014) state:

Rereading text and massed practice of a skill or new knowledge are by far the preferred study strategies of learners of all stripes, but they are also among the least productive. By massed practice we mean the single-minded, rapid-fire repetition of something you're trying to burn into memory, the "practice-practice-practice" of conventional wisdom. Cramming for exams is an example. Rereading and massed practice give rise to feelings of fluency that are taken to be signs of mastery, but for true mastery and durability these strategies are largely a waste of time (p.3).

From my observations, many Chinese students seem to be more used to writing dictations than original compositions and often struggle with analyzing reading passages. They would quote what the text says, but they often would not interpret it or practically apply it. This is where critical thinking goes hand in hand with plagiarism.

Combining materials from other sources is considered as the main requirement for creating one's own work. I can give an example from my own experience of getting a Master's degree in Liaoning Normal University in Dalian, China. The topic I chose for my thesis was "Creative Learning Strategies for Adult Language Learners." I combined the articles I had already written with some new research, included examples from my personal experience, results of the survey I conducted, and proposed lesson plans, among other activities. The work included approximately 50 pages at that point, written in Mandarin Chinese. After my professor looked through it, he simply drew a gigantic " $\mathrm{X}$ " across the front page as he said, "This is very interesting, but you can write your book only after you graduate. Right now, for your thesis, in order to graduate, you must go to the library, find other books on the topic and combine the quotes to make your work. You must only copy and paste what the others said. Take out everything that comes from you."

In my case, this meant rewriting the whole thesis, which was a challenging task to do considering how hard it was for me to find any material about creative learning strategies in Chinese libraries. Although I did eventually present my fully rewritten thesis, I was not satisfied with it. However, it served its purpose as an eye-opener for me. Taking such education system standards into consideration, it is not surprising to see Chinese students try to "copy and paste" here in the United States without having second thoughts. Therefore, most plagiarism cases I am familiar with occur among new Chinese students, who have not studied abroad before. Plagiarism, in this context, can mostly be seen just as a learning curve.

According to the estimate of WholeRen Education, a US company that caters to Chinese students, some 8,000 Chinese students were expelled from American universities in one year alone because of poor grades and cheating. Cheating on exams, plagiarism and finding other 
students to write papers for them were frequently cited as the specific causes of expulsion (Qi, 2015).

Instructors should be explicit in their expectations at the beginning of class about plagiarism and defining it for students. They need to be explicit in teaching what plagiarism looks like and give students examples so that they can understand. If they are low level and the instructor does not speak any Chinese, they might want to assign a specific time for this and ask another Chinese student of a higher level to interpret in order to avoid misunderstanding.

\section{Tests as the Only Measure of Success in a Program}

I found that Chinese professors tend not to give students participation points. They usually do not encourage class discussion or in-class practice. The educational system is focused on excellent academic grades and getting the highest possible score on tests. That is the reason why there may be some students with a 6.5 overall IELTS score (which is typically the entrance score for proving a student's English is adequately proficient for the university) that are not able to answer a simple "How are you?" question appropriately. Our ESL instructors at Park University, USA, repeatedly find that some Chinese students are surprised that they still need to put more effort towards improving their English even when they had already passed all required tests.

Making adjustments to grading criteria can assist with this issue. One helpful idea is to give students participation points separately from test points and even home assignment points. Instructors may want to explain in the beginning that participation points are about how active the students are in class, whether they volunteer to speak, ask and answer questions or just sit passively and remain silent. This way, they will be motivated to participate in class because there is an incentive to do so. For example, I usually divide the grade into three parts: one third class activity, one third oral presentations, and one third testing. Then I further break down class activity into participation (35\%), attendance (30\%) and home assignments (35\%). This lets the students see their class score progress unaffected by their success or failure on a test, while the overall score would reflect everything. There is also an option to not include some test scores into the final grade, as long as the institution can give instructors some flexibility in regards to grading. It is worthwhile to remember to stress to the students the importance of skills that they learn. They need to know that being able to use their newly acquired knowledge of English to communicate with others is far more important than their test scores because ideally, their ability to communicate will be reflected in a test score.

\section{Immaturity by US Standards}

From my observations in China, a number of students appeared immature (by US standards) until after graduation from college. I found that many students did not know how to cook, do laundry, buy groceries, put on make-up, drive and even swim. I would always see hundreds of Chinese adults using swim rings on the beach, since they never got a chance to learn how to swim. Almost all my Chinese student friends told me they have to eat out or buy snacks every day because they have not learned how to cook yet. Parents do everything for their children because they want them to be successful academically. 
In my opinion, the main reason seems to be that Chinese students basically live at school. They start attending numerous classes from as young as three years old and do enormous amounts of homework. I have taught two- and three-year-olds in Chinese language schools in a classroom environment, as well as 12 to 17 -year-olds who had to come to my English class on Sunday afternoons because it was the only time they had. They looked absolutely exhausted every time and it was hard to keep them motivated. By high school, students often stay at school until nine in the evening and then do homework until midnight after they come home, only to wake up at six in the morning to start it all over again. When asked about their hobbies, Chinese high school students will typically respond, "eating and sleeping." These are the only things within their reach that they enjoy, as they have no time for anything else.

Although instructors cannot parent their students, little things can make a big impact. This can include being available for their students after class to tell them about the university's food pantry, and check with them about how they like cafeteria food and whether they are getting along with their roommates. I find that it is best to talk to them in private to guard against the possibility of the students losing face.

\section{Privacy and Cross-Cultural Experiences}

Many Americans who live in China might initially say that such a thing as privacy simply does not exist there. In my experience, it is not unusual to hear a Chinese person asking about one's age, relationship status and salary at the first encounter. These are conversation topics as common as asking "How are you?" in the U.S. These questions do not necessarily have to be answered. They are wondering about age because they want to address the person appropriately, and they ask the rest simply because they are curious or want to break the ice and keep the conversation going.

Therefore, it is helpful to incorporate ideas of privacy from a North American perspective into ESL classes when appropriate. Instructors probably will not be asked many personal questions, but that does not mean the same for other students. ESL teachers will do students a favor and spare them from embarrassment if they share about the concept of privacy in America. Privacy extends further than asking questions. For example, I had students attempting to look over my shoulder on my computer screen as I was grading them. When I was a student in China, my roommate would even try to sit with me on the same chair and read my e-mails out loud. The point is simply that Chinese students come to the US with their understanding of privacy. The more we understand different perspectives of privacy, the less confusing some behaviors will appear.

\section{Concluding Thoughts}

Cultural challenges many Chinese students face are not insurmountable. Once instructors understand the reasons behind these challenges, it becomes easier to overcome them in the context of a multicultural environment. The ideas suggested here come from a North American perspective of an ESL instructor who studied and taught in China. As result, these ideas also reveal my US cultural values. The intent is for these ideas to serve as tools in the process of helping Chinese students adjust and learn English better and faster in the USA. This article 
covers only a few main cultural challenges that Chinese students face. It is important to remember that these are only common trends which may not fully apply to every Chinese student in class. 


\section{References}

Brown, P.C., Roediger III, H.L., \& McDaniel, M.A. (2014). Make it stick: the science of successful learning. The Belknap press of Harvard University Press, 3.

Cherry, K. (2018, October 31) Understanding collectivism cultures. How culture can influence behavior. Retrieved from https://www.verywellmind.com/what-are-collectivisticcultures-2794962

Li Z.Z, Li Y.M, Lei X.Y, Zhang D, Liu L, Tang S.Y, Chen L (2014, October 6) Prevalence of Suicidal Ideation in Chinese College Students: A Meta-Analysis. Retrieved from https://www.ncbi.nlm.nih.gov/pmc/articles/PMC4186746/

Scanlon, J. (2015) Q: Skills for success. Listening and Speaking. Level 1. Oxford University Press.

Qi, L.Y. (2015, May 29). U.S. Schools Expelled 8,000 Chinese Students. China Real Time Report. Retrieved from https://blogs.wsj.com/chinarealtime/2015/05/29/u-s-schoolsexpelled-8000-chinese-students-for-poor-grades-cheating/ 